\title{
PENDUGAAN LAPISAN AKUIFER AIR TANAH DENGAN METODE GEOLISTRIK RESISTIVITY KONFIGURASI SCLUMBERGER DI BERBAGAI WILAYAH INDONESIA
}

\author{
Nurwahida ${ }^{1}$, Hernawati ${ }^{1}$ \\ ${ }^{1}$ Jurusan Fisika UIN Alauddin Makassar \\ E-mail: wahidahaider4.gmail.com
}

\begin{abstract}
Abstrak: Penelitian ini bertujuan untuk mengetahui letak kedalaman yang diduga terdapat akuifer air tanah dan pengaruh nilai tahanan jenis terhadap letak akuifer air tanah. Pengujian ini dilakukan dengan memanfaatkan sifat resistivitas lapisan batuan di dalam bumi dengan metode resistivity konfigurasi schlumberger yaitu dengan menginjeksikan arus listrik kedalam bumi lewat dua elektroda arus dan menghitung potensialnya dari kedua elektroda potensial. Jarak kedalaman yang dijangkau pada saat pengukuran adalah setengah dari jarak elektroda arus. Hasil pembacaan dari berbagai jurnal diperoleh pendugaan sebaran akuifer air tanah berada pada lapisan batu pasir yang penyebarannya berbeda disetiap lokasi penelitian diduga berada pada kedalaman >40m di wilayah Jayapura, >94m jorong Tampus Kangarian Ujung Gading, 30-90m kab. Jombang, 22-126m bandara Adi Soemarmo, 2-15 desa Sungai jati kalimantan Selatan, 10-59m desa Takuti kab. Banjar kalimantan Selatan, 127,76m wilayah Cepu Blora Jawa Tengah,6,5-40m desa Slamparejo Kec. Jabung Kab malang dan 1-22,30m kampus Tegal Boto universitas Jember. Semakin kecil nilai resestivitas lapisan batuan maka pendugaan ditemukannya akuifer air tanah semakin besar.
\end{abstract}

Kata kunci : Air tanah, Akuifer, Geolistrik, Tahanan jenis.

\section{PENDAHULUAN}

$\mathrm{D}$ ewasa ini pertumbuhan penduduk dan pembangunan semakin meningkat. Pertumbuhan penduduk dan kemajuan pembangunan menyebabkan meningkatnya kebutuhan akan air bersih. Air adalah salah satu kebutuhan dasar semua makhluk hidup terutama bagi manusia. Sementara itu, kerusakan lingkungan dan pencemaran telah menyebabkan sumber air bersih di permukaan terus berkurang (Arif Budiman dkk, 2013). Peningkatan penggunaan air terkadang tidak disertai pengelolaan sumber air yang baru disebabkan kurangnya informasi mengenai potensi sumber air tanah. Potensi sumber air tanah berbeda-beda sesuai dengan kondisi geologi sekitarnya (Serli Birlina H dkk, 2013). Sebagian daerah terdapat PDAM yang selama ini diusahakan oleh pemerintah untuk mensuplai air bersih merasa kewalahan akibat permintaan yang terus bertambah. Agar kebutuhan akan air bersih baik kualitas maupun kuantitas terpenuhi maka diperlukan sumber air bersih lain berupa air tanah (Virman, 2014). Air tanah merupakan salah satu sumber kebutuhan bagi kehidupan makhluk 
hidup di muka bumi (Gusfan H. \& Widodo J. S, 2008). Ketersediaan air dari waktu ke waktu relatif tetap karena mengikuti daur hidrologi, walaupun demikian ketersediaan air dirasakan semakin terbatas. Hal ini antara lain disebabkan oleh meningkatnya jumlah penduduk dan pembangunan ekonomi, kemarau yang berkepanjangan. Selain keterbatasan pasokan air tanah, penggunaan air tanah yang berlebihan dapat mempengaruhi kualitas air tanah tersebut (Virman, 2014). Untuk daerah pesisir penggunaan air tanah yang berlebihan menyebabkan terjadinya intrusi air laut dan menimbulkan perubahan kualitas air tanah. Mengingat faktor kondisi geologi juga berpengaruh terhadap potensi sumber air tanah, maka perlu dilakukan kajian mengenai potensi sumber air tanah, dan deteksi lapisan akuifer air berdasarkan pada nilai tahanan jenis batuan dengan metode geolistrik resistivity.

\section{Rumusan Masalah}

Rumusan masalah penelitian ini adalah:

1. Di mana letak kedalaman yang diduga terdapat akuifer air tanah dengan menggunakan metode geolistrik resistivity konfigurasi Schlumberger?

2. Bagaimana pengaruh nilai tahanan jenis terhadap penyebaran akuifer air tanah?

\section{Tujuan}

Tujuan penelitian ini adalah:

1. Mengetahui letak kedalaman yang diduga terdapat akuifer air tanah dengan menggunakan metode geolistrik resistivity konfigurasi Schlumberger.

2. Mengetahui pengaruh nilai tahanan jenis terhadap penyebaran akuifer air tanah.

\section{Integrasi Ayat}

Pada sekitar tahun 1900 an, geolog Badon Ghyben dan Herzberg mengemukakan prinsip bahwa air asin akan mengapung pada air tawar, sehingga pada pertemuan tersebut merupakan zona difusi yang membuat tidak dapat bercampurnya asin dengan air tawar atau yang dikenal sebagai interface air asin-tawar, sehingga kedua jenis air ini tidak bisa saling melampaui. Prinsip ini dibuktikan pada pertemuan antara Laut Atlantik dan Laut Mediteran di Selat Gibraltar yang tidak bisa bercampur airnya. Sementara itu sejak 15 abad yang lalu, tidak mungkin bercampurnya air laut dengan air tawar sudah dijelaskan oleh Allah melalui Rasul-Nya SAW, dan berfirman dalam surat Ar-Rahman (55)/19-20:

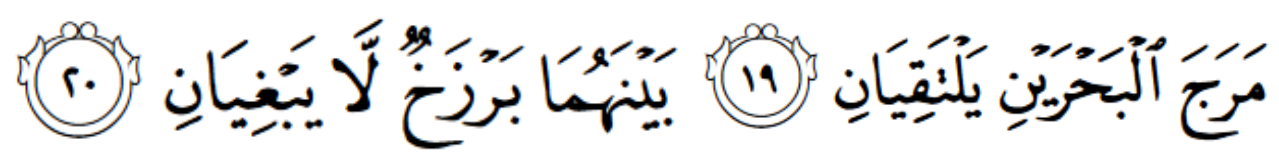

"Dia membiarkan dua lautan mengalir yang keduanya Kemudian bertemu, antara keduanya ada batas yang tidak dilampaui masing-masing”

Atau pada surat Al Furqon (25)/53

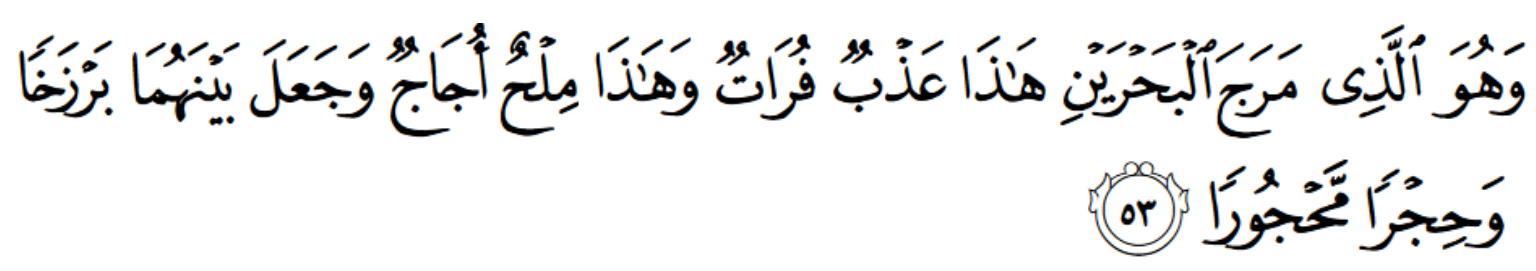


" Dan Dialah yang membiarkan dua laut yang mengalir (berdampingan); yang Ini tawar lagi segar dan yang lain asin lagi pahit; dan dia jadikan antara keduanya dinding dan batas yang menghalangi"

Di dalam tanah ada akuifer, menyaring infiltrasi dari hujan, mengalirkan sekaligus menyimpan, kita kaitkan dengan jenis batuan, porositas, water-rock interaction, dst. Karena itu Allah menciptakan gunung di dalam surah Al-Mursalat (77)/27

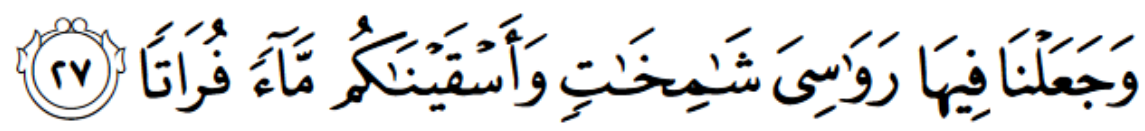

"Dan kami jadikan padanya gunung-gunung yang tinggi, dan kami beri minum kamu dengan air tawar?"

Dengan ayat ini akan lebih mudah kita menjelaskan, ada gunung, ada material piroklastis, porositas bagus, menyaring, menyimpan, dan mengalirkan airtanah, sehingga simpanan airtanah melimpah dan rasanya tawar. Selanjutnya, karena nilai permeabilitas di lereng atau dataran gunung pasti tinggi/cepat, tidak terlalu banyak water-rock interaction, sehingga kandungan unsur terlarut tidak begitu banyak, sehingga airnya berasa segar/tawar.

\section{Metode Geolistrik}

Metode yang sering digunakan untuk menduga kondisi air bawah tanah adalah metode geolistrik tahanan jenis. Pendeteksian dilakukan berdasarkan sifat fisika batuan terhadap arus yang diinjeksikan kedalam tanah, dimana setiap batuan mempunyai sifat harga hambatan jenis yang berbeda (Astawa, 2009:57 dalam Dwi Wahyu, 2012). Berdasarkan hal tersebut, apabila arus listrik searah (DC) dialirkan melalui dua buah elektroda arus A dan B, kemudian diukur beda potensialnya pada titik MN (Todd, D.K, 1980 dalam Dwi Wahyu, 2012).

Metode geolistrik adalah metode geofisika yang dapat menginterprestasi jenis batuan atau mineral di bawah permukaan berdasarkan sifat kelistrikan dari batuan penyusunnya (Yulianto \& Widodo, 2008:2 dalam Dwi Wahyu, 2012). Tujuan dari metode ini adalah untuk menetahui sifat kelistrikan medium batuan di bawah permukaan yang berhubungan dengan kemampuannya untuk menghantarkan listrik atau resistivitas (Todd, D.K, 1980 dalam Dwi Wahyu, 2012). Metode geolistrik dapat digunakan untuk mendeteksi adanya akuifer dalam tanah (Dwi Wahyu, 2012).

Prinsip kerja pendugaan geolistrik adalah mengukur tahanan jenis (resistivity) dengan mengalirkan arus listrik kedalam batuan atau tanah melalui elektroda arus (current electrode), kemudian arus diterima oleh elektroda potensial. Beda potensial antara dua elektroda tersebut diukur dengan volt meter dan dari harga pengukuran tersebut dapat dihitung tahanan jenis semua batuan dengan menggunakan rumus sebagai berikut (Anonim, 1992 dan Todd, 1980 Gusfan H. \& Widodo J. S, 2008)

$\rho=\frac{2 \pi \cdot a \mathrm{~V}}{I}$

$\rho$ adalah tahanan jenis, $2 \pi$ konstanta, $\mathrm{V}$ beda potensial, I kuat arus dan a adalah jarak elektroda (Gusfan H. \& Widodo J. S, 2008). 


\section{Konsep Resistivitas Semu}

Pengukuran geolistrik dilakukan dengan menginjeksikan arus listrik ke bumi, kemudian mengamati pengaruhnya dipermukaan bumi (Todd, D. K, 1980 dalam Dwi Wahyu 2012). Pengukuran geolistrik ini menggunakan metode resistivitas. Pada metode resisitivitas, arus yang masuk dapat diasumsikan bahwa bumi homogen isotropis (Dwi Wahyu, 2012). Metode ini dilakukan dengan cara memindahkan elektroda dengan jarak tertentu maka akan diperoleh harga-harga tahanan jenis pada kedalaman yang sesuai dengan jarak elektroda. Harga tahanan jenis dari hasil perhitungan kemudian diplot terhadap kedalaman (jarak elektroda) pada kertas 'log-log' yang merupakan kurva lapangan. Selanjutnya kurva lapangan tersebut diterjemahkan menjadi jenis batuan dan kedalamannya. Prinsip konfigurasi geolistrik ditunjukkan pada Gambar 1. jenis pada kedalaman yang sesuai dengan jarak elektroda. Harga tahanan jenis dari hasil perhitungan kemudian diplot terhadap kedalaman (jarak elektroda) pada kertas ' $\log -\log$ ' yang merupakan kurva lapangan. Selanjutnya kurva lapangan tersebut diterjemahkan menjadi jenis batuan dan kedalamannya. (Gusfan H. \& Widodo J. S, 2008).

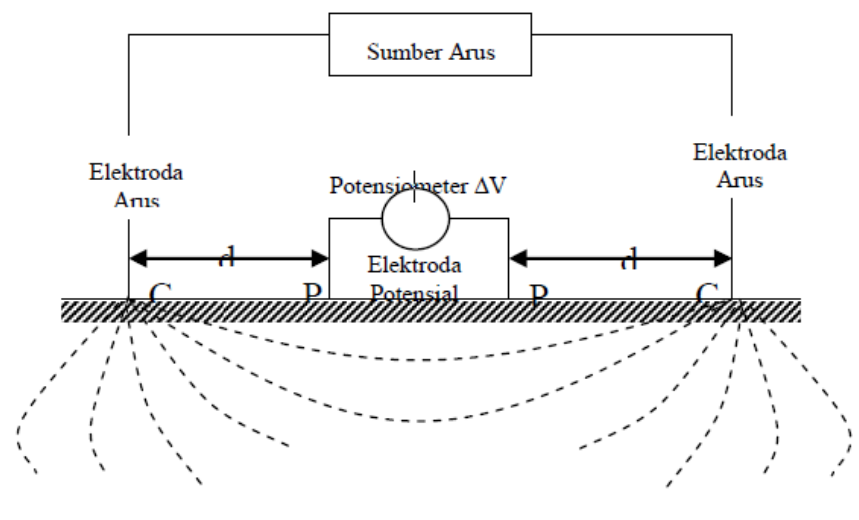

Gambar 1. Konfigurasi Geolistrik

Pengukuran resitivitas suatu titik soundingdilakukan dengan jalan mengubah jarak elektrode secara sembarang tetapi mulai dari jarak elektrode kecil kemudian membesar secara gradual. Jarak antar elektrode ini sebanding dengan kedalaman lapisan batuan yang terdeteksi. Makin besar jarak elektrode maka makin dalam lapisan batuan yang dapat diselidiki. Interpretasi data resistivitas didasarkan pada asumsi bahwa bumi terdiri dari lapisan-lapisan tanah dengan ketebalan tertentu dan mempunyai sifat kelistrikan homogen isotrop, dimana batas antar lapisan dianggap horisontal (Gusfan $\mathrm{H}$. \& Widodo J. S, 2008).

Metode ini didasarkan pada anggapan bahwa bumi mempunyai sifat homogen isotropis. Dengan asumsi ini, tahanan jenis yang terukur merupakan tahanan jenis yang terukur merupakan tahanan jenis yang sebenarnya dan tidak tergantung pada spasi elektroda. Namun pada kenyataannya, bumi terdiri atas lapisan-lapisan dengan tahanan jenis yang berbeda-beda, sehingga potensial yang terukur merupakan pengaruh dari lapisan-lapisan tersebut. Dengan demikian tahanan jenis yang terukur bukan merupakan harga tahanan jenis untuk satu lapisan saja, terutama untuk spasi elektroda yang lebar. Dalam hal ini yang terukur adalah tahanan jenis semu (apparent resistivity $\rho a$ )[4]. (Ramadhan K. N. F. Dkk, 2017)

$$
\rho a=K \frac{\Delta V}{I}
$$


Dengan memindahkan elektroda dengan jarak tertentu maka akan diperoleh harga-harga tahanan. Asumsi tersebut dapat memberikan gambaran bahwa pada saat melakukan pengukuran, besaran resistivitas menunjukkan besaran resistivitas yang tidak bergantung pada jarak elektroda potensial yang dipakai. Pengukuran tersebut tidak berlaku pada kondisi bumi yang sesungguhnya, pada kondisi bumi yang sesungguhnya bumi terdiri atas lapisan-lapisan dengan resistivitas yang berbeda-beda, perbedaan lapisan bumi tersebut menyebabkan resistivitas yang terukur bergantung pada jarak elektroda potensial. Besar resistivitas yang terukur merupakan resistivitas semu atau apparent resistivity (Todd, D.K, 1980 dalam Dwi Wahyu, 2008).

Survei resistivitas akan memberikan gambaran tentang distribusi resistivitas bawah permukaan. Harga resistivitas tertentu akan berasosiasi dengan kondisi geologi tertentu. Untuk mengkonversi harga resistivitas ke dalam bentuk geologi diperlukan pengetahuan tentang tipikal dari harga resistivitas untuk setiap tipe material dan struktur daerah survey. Harga resistivitas batuan, mineral, tanah dan unsur kimia secara umum telah diperoleh melalui berbagai pengukuran dan dapat dijadikan sebagai acuan untuk proses konversi (Telford, et al., 1990). Nilai resistivitas sebenarnya dapat dilakukan dengan cara pencocokan (matching) atau dengan metode inversi. Pada penelitian ini dilakukan dengan metode inversi, menggunakan program IPI2WIN. (Gusfan H. \& Widodo J. S, 2008)

\section{Akuifer}

Formasi-formasi yang berisi/ menyimpan air tanah disebut sebagai akuifer (Indarto, 2012). Jumlah air tanah yang dapat diperoleh di setiap daerah tergantung pada sifat-sifat akuifer yang ada di bawahnya. Akuifer atau lapisan pembawa air atau lapisan permeabel adalah batuan yang mempunyai susunan yang dapat mengalirkan air (Indarto, 2012: 44 dalam Dinisa H dkk 2016).

Akuifer adalah lapisan bawah permukaan yang dapat menyimpan dan mengalirkan air. Formasi geologi yang mengandung air dan memindahkannya dari satu titik ke titik yang lain dalam jumlah yang mencukupi untuk pengembangan ekonomi disebut suatu lapisan akuifer (Ray et al.,1989). Akuifer dapat juga diartikan sebagai lapisan pembawa air atau lapisan permeabel. (Dinisa Hanifa, 2016)

\section{Konfigurasi Elektroda Schlumberger}

Terdapat beberapa konfigurasi atau cara menyusun elektroda untuk melakukan pengukuran bawah permukaan dalam metode geolistrik, seperti konfigurasi Wenner, Schlumberger, Pole-Pole, Pole- Dipole, Dipole-Dipole. Pada pengukuran sounding yaitu pengukuran bawah permukaan dengan tujuan untuk mengetahui sebaran titik geolistrik secara vertikal ke bawah dengan kedalaman yang cukup dalam, konfigurasi yang cocok digunakan adalah konfigurasi Schlumberger. (Dwi Wahyu, 2008)

Pengukuran sounding adalah pengukuran bawah permukaan tanah yang bertujuan untukmengetahui sebaran titik geolistrik secara vertikal ke bawah tanah, konfigurasi yang tepat untuk digunakan adalah konfigurasi Schlumberger. Konfigurasi Schlumberger diasumsikan $\mathrm{M}$ dan $\mathrm{N}$ digunakan sebagai elektroda potensial, A dan B sebagai elektroda arus. Untuk konfigurasi elektroda Schlumberger, jarak elektroda arus jauh lebih besar dari jarak elektroda potensial. Secara garis besar aturan elektroda ini dapat dilihat pada Gambar 2, sehingga diketahui bahwa jarak antar elektroda arus adalah $\mathrm{AB} / 2$, sedangkan jarak antar elektroda potensial adalah MN/2. (Casa Setia dkk, 2013) 


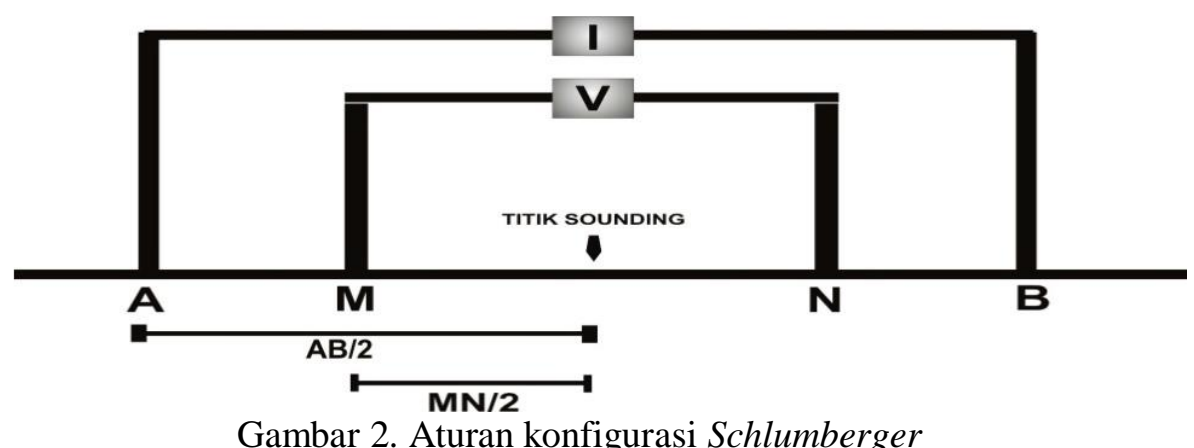

Pendugaan geolistrik sounding dilakukan untuk memperolehan data penelitian menggunakan konfigurasi elektroda schlumberger. (Casa Setia dkk, 2013)

$$
\begin{aligned}
& K=\frac{2 \pi}{\left(\frac{1}{\frac{A B}{2}} \frac{1}{2}\right)-\left(\frac{1}{\frac{A B}{2}}+\frac{1}{\frac{M N}{2}}\right)-\left(\frac{1}{\frac{A B}{2}}+\frac{1}{\frac{M N}{2}}\right)+\left(\frac{1}{\frac{A B}{2}} \frac{1}{2}\right)} \\
& K=\frac{2 \pi}{2\left(\frac{1}{\frac{A B}{2}} \frac{1}{\frac{M N}{2}}\right)-2\left(\frac{\left.\frac{1}{\frac{A B}{2}}+\frac{1}{\frac{M N}{2}}\right)}{2}\right.} \\
& K=\frac{\pi}{\left(\frac{1}{\left.\frac{A B}{2} \frac{\frac{M N}{2}}{2}\right)-\left(\frac{1}{\frac{A B}{2}}+\frac{1}{\frac{M N}{2}}\right)}\right.} \\
& K=\frac{\pi\left(\frac{A B}{2} \frac{M N}{2}\right)-\left(\frac{A B}{2}+\frac{M N}{2}\right)}{2\left(\frac{M N}{2}\right)} \\
& K=\frac{\pi\left(\frac{A B}{2}\right)^{2}-\left(\frac{M N}{2}\right)^{2}}{2\left(\frac{M N}{2}\right)}
\end{aligned}
$$

\section{Air Tanah}

Air tanah (groundwater) merupakan air yang berada di bawah permukaan tanah yang terdapat pada lapisan akuifer. Karakteristik utama yang membedakan air tanah dari air permukaan adalah pergerakan yang sangat lambat dan waktu tinggal yang sangat lama, dapat mencapai puluhan bahkan ratusan tahun. Air tanah dapat dibedakan menjadi dua macam, yaitu air tanah tidak tertekan (bebas) dan air tanah tertekan. Air tanah bebas adalah air tanah dari akuifer yang hanya sebagian terisi air, terletak pada suatu dasar yang kedap air, dan mempunyai permukaan bebas. Air tanah tertekan adalah air tanah dari akuifer yang sepenuhnya jenuh air, dengan bagian atas dan bawah dibatasi oleh lapisan yang kedap air (Effendi, 2013 dalam Putri K. W. Dkk, 2016). Sifat batuan terhadap air tanah dibedakan menjadi:

1. Akuifer, merupakan batuan yang dapat mengalirkan air yang cukup berarti misal pasir, kerikil, batu pasir, batu gamping yang berlubanglubang, lava yang retak-retak.

2. Akuiklud, merupakan batuan yang hanya dapat menyimpan air dan tidak dapat mengalirkan. 
3. Akuifug, merupakan batuan yang tidak dapat menyimpan dan tidak dapat mengalirkan air.

4. Akuitar, merupakan batuan yang dapat mengalirkan air dengan potensi kecil (Supadi, 2005 dalam Putri K. W. Dkk, 2016).

Air bawah permukaan adalah sejumlah air di ba wah permukaan bumi yang dapat dikumpulkan dengan sumur-sumur, terowongan atau sistem drainase, atau aliran yang secara alami mengalir ke permukaan tanah melalui pancaran atau rembesan. Kebanyakan air tanah berasal dari hujan. Air hujan yang meresap ke dalam tanah menjadi bagian dari air tanah, perlahan-lahan mengalir ke laut, atau mengalir langsung dalam tanah atau dipermukaan dan bergabung dengan aliran sungai. Banyaknya air yang meresap ke tanah bergantung pada ruang dan waktu, selain itu juga dipengaruhi kecuraman lereng, kondisi material permukaan tanah dan jenis serta banyaknya vegetasi dan curah hujan.

Sebagian air yang meresap tidak bergerak jauh karena tertahan oleh daya tarik molekuler sebagai lapisan pada butiran-butiran tanah. Sebagian menguap ke atmosfer dan sisanya merupakan cadangan bagi tumbuhan selama belum ada hujan. Air yang tidak tertahan dekat permukaan menerobos ke bawah sampai zona dimana seluruh ruang terbuka pada sedimen atau batuan terisi air (jenuh air). Air dalam zona saturasi (zone of saturation) ini dinamakan air tanah (ground water). Batas atas zona ini disebut muka air tanah (water table). Lapisan tanah, sedimen atau batuan diatasnya yang tidak jenuh air disebut zona aerasi (zone of aeration). (Romandah F. K. N dkk

\section{METODE PENELITIAN}

Metode yang digunakan adalah metode studi literatur yang dilakukan selama satu bulan. Data yang diperoleh dari berbagai jurnal menggunakan metode resistivity konfigurasi schlumberger tersebar di berbagai wilayah yaitu kampus Tegal boto Universitas Jember desa Slamparejo, kecamatan Jabung kabupaten Malang, distrik Jaya Pura Selatan, Jorong Tampus Kanagarian Ujung Gading kecamatan Lembah Malintang kabupaten Pasaman barat Sumatera barat, kabupaten Jombang jawa timur, daerah bandara Adi Soemarmo Solo Jawa tengah, desa Sungai Jati kecamatan Mataraman kabupaten Banjar Kalimantan selatan, desa Takuti Kabupaten Banjar Kalimantan selatan, wilayah Cepu Blora Jawa tengah, daerah Istimewa Yogyakarta, desa Slamparejo kecamatan Jabung kabupaten Malang, distrik Waisai kota kabupaten Raja Ampat provinsi Papua barat.

\section{Instrumen Penelitian}

Alat yang digunakan dalam penelitian ini adalah geolistrik (resistivity meter)

McOHM-EL Model 2119 dengan spesifikasi sebagai berikut:

- Resistivity meter with borehole logging function

- 24 bit Delta-Sigma A/D converter

- High resolution thermal printer

- Floppy Disk storage 720KB /1.2MB /1.44MB

- High transmitting voltage $400 \mathrm{~V}$

- Low power-external 12 VDC

- $\quad$ Light weight 8Kg McOHM Model 2119 
Alat tersebut dilengkapi dengan:

- Patok untuk mengetahui penempatan elektroda yang akan dipasang.

- Palu digunakan untuk menancapkan elektroda potensial dan elektroda arus di tanah.

- Accu (elemen kering) sebagai sumber arus.

- Elektroda (elektroda potensial dan elektroda arus)

- Meteran digunakan untuk mengukur panjang lintasan yang akan diteliti.

- Kabel listrik digunakan sebagai kabel penghubung.

- Tabel data untuk menulis data hasil pengukuran.

- Alat tulis menulis digunakan untuk menulis data dari hasil pengukuran.

Dalam penelitian ini dilakukan beberapa tahapan yaitu survei lapangan yaitu perencanaan panjang lintasan, penentuan titk awal pengukuran serta target kedalaman penelitian, kemudian pengambilan data lapangan, pengolahan data.

\section{Pengambilan Data Lapangan}

Penelitian ini menggunakan teknik pengukuran dilakukan secara sounding (1D). Teknik pengukuran secara sounding (1D) digunakan untuk mengetahui sebaran harga resistivitas pada suatu areal tertentu. Perpindahan Elektroda Secara Sounding.

Tahap-tahap pengambilan data di lapangan adalah sebagai berikut:

1. Menancapkan elektroda pada permukaan tanah dengan spasi yang teratur.

2. Membentangkan kabel yang digunakan sebagai penghantar arus dan potensial yang menghubungkan antar elektroda dengan alat resistivitymeter.

3. Memasang kabel ke elektoda untuk menghubungkan kabel dengan elektroda agar arus atau potensial dapat terhubung pada elektroda.

4. Menghubungkan terminal kabel, dan kabel sudah terhubung dengan resistivitimeter

5. Langkah selanjutnya mentransfer data dari manual dengan komputer.

\section{Metode Pengolahan Data}

Pengolahan data geolistrik menggunakan sistem komputerisasi yang diawali dengan pengolahan data untuk mencari resistivitas semu, kemudian diolah menggunakan software Ipi2Win untuk memperoleh penampang 1D. Software Ipi2Win menggambarkan harga resistivitas dari hasil perhitungan di lapangan sehingga dihasilkan gambaran pelapisan batuan, berupa nilai resistivitas. Data berupa ketinggian pengukuran dan koordinat survei dari GPS (Global Position Satelite) di transfer ke komputer menggunakan kabel usb dan di terjemahkan menggunakan software basecamp dan navigasi navnet_Garmin_v247-NT. Selain software Ipi2Win sebagian wilayah penelitian juga menggunakan PROGRESS V 3.0 untuk pengolahan datanya, kemudian penggambaran hasil penampang litologi dengan software rockwork dan nilai resistivitas titik tiap soundingnya dipetakan dengan software Surfer. 


\section{HASIL DAN PEMBAHASAN}

Tabel 1. Data Hasil Penelitian

\begin{tabular}{llcc}
\hline \multicolumn{1}{c}{ Peneliti } & \multicolumn{1}{c}{ Wilayah } & \multicolumn{1}{c}{$\begin{array}{c}\text { Tahanan jenis } \\
(\mathbf{\Omega} \mathbf{~ m})\end{array}$} & $\begin{array}{c}\text { Kedalaman } \\
(\mathbf{m})\end{array}$ \\
\hline Virman, 2014 & Distrik jaya pura selatan & $10-28,3$ & $>40$ \\
\cline { 2 - 4 } & Distrik Abepura & 19 & $>50$ \\
\hline Arif Budiman, 2013 & $\begin{array}{l}\text { Jorong Tampus Kanagarian Ujung } \\
\text { Gading, Sumatra Barat }\end{array}$ & $42-393$ & $>94$ \\
\hline $\begin{array}{l}\text { Serli Birlina H dkk, } \\
2013\end{array}$ & $\begin{array}{l}\text { Kabupaten Jombang, } \\
\text { Jawa Timur }\end{array}$ & $20-135$ & $30-90$ \\
\hline Caga Setia,2013 & $\begin{array}{l}\text { Daerah Bandara Adi Soemarmo, } \\
\text { Solo, Jawa Tengah }\end{array}$ & $28-412$ & $22-126$ \\
\hline Dinisa Hanifa, 2016 & $\begin{array}{l}\text { Di Desa Sungai } \\
\text { Jati, } \\
\text { Kalimantan Selatan }\end{array}$ & $2-15$ \\
\hline $\begin{array}{l}\text { Putri Ika Wardani } \\
\text { dkk, 2016 }\end{array}$ & $\begin{array}{l}\text { Desa Takuti Kabupaten Banjar } \\
\text { Kalimantan Selatan }\end{array}$ & $16-108$ & $10-59$ \\
\hline $\begin{array}{l}\text { Romandah K. N. F. } \\
\text { Dkk, 2017 }\end{array}$ & $\begin{array}{l}\text { Wilayah Cepu, Blora, Jawa } \\
\text { Tengah }\end{array}$ & 5,28 & 127,76 \\
\hline $\begin{array}{l}\text { Dwi Wahyu } \\
\text { Pujomiarto, 2017 }\end{array}$ & $\begin{array}{l}\text { Desa Slamparejo Kecamatan } \\
\text { Jabung Kabupaten Malang }\end{array}$ & $11-400$ & $6,5-40$ \\
\hline $\begin{array}{l}\text { Gusfan Halik dan } \\
\text { Jojok Widodo S., }\end{array}$ & $\begin{array}{l}\text { Kampus Tegal Boto Universitas } \\
\text { Jember }\end{array}$ & $10-70$ & $1-22,30$ \\
\hline
\end{tabular}

Metode geolistrik adalah metode geofisika yang dapat menginterprestasi jenis batuan atau mineral di bawah permukaan berdasarkan sifat kelistrikan dari batuan penyusunnya (Yulianto \& Widodo, 2008:2 dalam Dwi Wahyu, 2012). Tujuan dari metode ini adalah untuk menetahui sifat kelistrikan medium batuan di bawah permukaan yang berhubungan dengan kemampuannya untuk menghantarkan listrik atau resistivitas (Todd, D.K, 1980 dalam Dwi Wahyu, 2012). Metode geolistrik dapat digunakan untuk mendeteksi adanya akuifer dalam tanah (Dwi Wahyu, 2012). Pengolahan data geolistrik menggunakan sistem komputerisasi yang diawali dengan pengolahan data untuk mencari resistivitas semu, kemudian diolah menggunakan software Ipi2Win untuk memperoleh penampang 1D. Software Ipi2Win menggambarkan harga resistivitas dari hasil perhitungan di lapangan sehingga dihasilkan gambaran pelapisan batuan, berupa nilai resistivitas.

Berdasarkan data hasil penelitian di atas di peroleh hasil interpretasi berupa lapisan-lapisan batuan yang terdiri dari lapisan batu pasir, pasir lempungan, pasir vulkanik, pasir, lempung pasiran, breksi, kerikil, kerakal, batu pasiran, lempung lanau, aluvial, batu pasir kompak lempung, lempung, batu pasir lempungan, pasir tufa, batu pasir kuarsa, tufa lempung, tufa pasiran, batu lempung, lempung sisipan gamping, lapisan lapuk, tanah, edapan aluvium dan tanah timbunan. Lapisan akuifer diduga berada pada lapisan yang mengandung pasir dan memiliki nilai resistivitas yang kecil karena lapisan tersebut mengandung pori yang dapat menampung dan mengalirkan air. Sedangkan lapisan lain yang memiliki nilai resistivitas yang tinggi dapat bersifat impermeable atau lapisan kedap air seperti lempung. Semakin kecil tahanan jenis maka kemungkinan ditemukannya akuifer air tanah semakin besar. 


\section{KESIMPULAN}

Kesimpulan penelitian ini adalah:

1. Letak akuifer air tanah didug berada pada kedalaman $>40 \mathrm{~m}$ di wilayah Jayapura, $>94 \mathrm{~m}$ jorong Tampus Kangarian Ujung Gading, 30-90m kab. Jombang, 22-126m bandara Adi Soemarmo, 2-15 desa Sungai jati kalimantan Selatan, 10-59m desa Takuti kab. Banjar kalimantan Selatan, 127,76m wilayah Cepu Blora Jawa Tengah,6,5-40m desa Slamparejo Kec. Jabung Kab malang dan 1-22,30m kampus Tegal Boto universitas Jember.

2. Semakin kecil nilai resestivitas lapisan batuan maka pendugaan ditemukannya akuifer air tanah semakin besar.

\section{DAFTAR PUSTAKA}

Birlana, Serli H. Dkk. 2013. Interpretasi Data Geolistrik untuk Memetakan Potensi Air Tanah dalam Menunjang Pengembangan Data Hidrogeologi di Kabupaten Jombang Jawa Timur. Jurnal Fisika dan Aplikasinya. Vol 9 no 2.

Budiman, Arif dkk. 2013. Pendugaan Potensi Air Tanah Dengan Metode Geolistrik Tahanan Jenis Konfigurasi Schlumberger. Jurnal Ilmu Fisika. ISSN 1979-4657 Vol 5 no 2.

Febriana, Romandah Kusuma Nur dkk. 2017. Identifikasi Sebaran Aliran Air Bawah Tanah(Groundwater) dengan Metode Vertical Electrical Sounding (VES) Konfigurasi Schlumberger di Wilayah Cepu Blora Jawa Barat. Jurnal Sains dan Seni ITS. 25280-51258 vol 6 no 2 .

Halik, Gusfan dan Widodo Jojok S. 2008. Pendugaan Potensi Air Tanah Dengan Metode Geolistrik Konfigurasi Schlumberger Di Kampus Tegal Boto Universitas Jember. Jurnal.

Hanifa, Dinisa dkk. 2016. Penentuan Lapisan Akuifer Air Tanah Dengan Metode Geolistrik Konfigurasi Schlumberger Di Desa Sungai Jati Kecamatan Mataraman Kabupaten Banjar Kalimantan Selatan. Jurnal Fisika Fluks. Vol 13 no 1.

Pujumiarto, Dwi Wahyu. Aplikasi Metode Geolistrik Resistivitas Konfigurasi Schlumberger Untuk Mengidentifikasi Lapisan Akuifer Di Desa Slamparejo Kecamatan Jabung Kabupaten Malang.

Setia, Caga dkk. 2013. Identifikasi Sumber Air Tanah dalam Berdasarkan Analisis Data Resistivitas di Daerah Bandara Adi Soemarmo Solo Jawa Tengah. Journal of Applied Physics. ISSN:2089 - 0133 vol 3 no 2

Virman. 2014. Aplikasi Metode Geolistrik untuk Menentukan Model Penyebaran Air Tanah Daerah Distrik Jayapura Selatan, Kota Jayapura. Jurnal.

Wardani, Putri Ika dkk. 2016. Pendugaan Air Tanah Dengan Metode Geolistrik Schlumberger Di Desa Takuti Kabupaten Banjar Kalimantan Selatan. Jurnal Fisika Fluks. Vol 13 no .

Gisland, Grand S. 2017. Potensi Akuifer Air Tanah Pada Batuan Sedimen Tersier Berdasarkan Analisis Data Geolistrik Di Distrik Waisai Kota Kabupaten Raja Ampat, Provinsi Papua Barat. Bulletin of Scientific Contribution. Vol 15 no 2. 